\title{
ORIGINAL ARTICLE \\ Neuroprotective effects of chloroform and aqueous fractions of noni juice against t-Butyl hydroperoxide-induced oxidative damage in SH-SY5Y cells
}

\author{
Jianguo Chen ${ }^{\dagger \dagger}$, Xue Shi ${ }^{2+}$,Yang Chen², Hanqiao Liang ${ }^{3}$, Chi Cheng ${ }^{3 *}$ and Qiyang He ${ }^{2 *}$ \\ I'Inner Mongolia Mengniu Diary Industry Group Co, Ltd, China; ${ }^{2}$ Institute of Medicinal Biotechnology, Peking Union \\ Medical College and Chinese Academy of Medical Sciences, Beijing, China; ${ }^{3}$ China Center of Industrial Culture \\ Collection, China National Research Institute of Food and Fermentation Industries, Beijing, China
}

\section{Abstract}

Oxidative stress is more likely to cause damage to neuronal cells and mediates some neurodegenerative disorders. It is well known that natural antioxidants can prevent oxidative stress damage and become a potential therapeutic strategy. Noni juice obtained from the fruit of the tree Morinda citrifolia, as a folk medicine, has been used for over two thousand years. In the current study, the neuroprotective effect and mechanism of noni juice extracts against tert-Butyl hydroperoxide (TBHP)-induced SH-SY5Y cell damage were investigated. The results demonstrated that chloroform fraction (CF) and aqueous fraction (AF) of noni juice protected SH-SY5Y cells against TBHP-induced oxidative stress and the associated apoptosis effectively. CF and AF treatment significantly weakened the TBHP-induced cytotoxicity, reactive oxygen species generation, mitochondrial membrane depolarization, and apoptotic features. $\mathrm{CF}$ and AF restored cellular antioxidant enzyme activity; upregulated expression of heme oxygenase-1, catalase, and superoxide dismutase-1; and increased the nuclear accumulation of nuclear factor-erythroid 2 related factor 2 (Nrf2). The antioxidant and neuroprotection potential of $\mathrm{CF}$ may account for its high total phenolic and flavonoid content, while AF may be rich in polysaccharides. These results suggest that $\mathrm{CF}$ and $\mathrm{AF}$ exhibit antioxidant defense through the upregulation of Nrf2 along with endogenous antioxidants and reduce apoptosis via inhibiting the mitochondrial pathway to protect SH-SY5Y cells damaged by TBHP. CF and AF might be developed as agents for neurodegeneration prevention or therapy.

Keywords: noni juice; neuroprotective; oxidative stress; Nrf2; apoptosis

$\mathrm{C}$ ompared with other organs, lower levels of antioxidant enzymes, higher metabolic activity and higher content of polyunsaturated fatty acids in the brain, neurons are more susceptible to oxidative stress $(1,2)$. The imbalance between oxidants and antioxidants may destroy the redox signal and lead to oxidative stress. Excessive oxidative stress can cause oxidative damage in biomolecules such as DNA, proteins, lipids, and carbohydrates. Many neurodegenerative diseases, such as Alzheimer's disease, Parkinson's disease, Huntington's disease, and amyotrophic lateral sclerosis, may be caused by neuronal damage resulting from intracellular oxidative stress (3-8). Increasing evidence suggests that natural antioxidants may attenuate neurotoxicity and play important roles in prevention and treatment of oxidative stress-induced neurodegenerative diseases (9-12).
Herbal extracts rich in antioxidants, as traditional medications, have potent antioxidant activity and prevent neurodegenerative diseases caused by oxidative stress. Morinda citrifolia L. is commonly known as 'noni' and has been extensively used as a folk remedy for 2000 years in Polynesia, Australia, Southeast Asia, and Hawaii. Noni juice, obtained from the fruit of $M$. citrifolia, is reported to have many bioactive phytochemical constituents, such as glycosides, iridoids, anthraquinones, flavonoids, phenolic acid, and coumarins (13-15). It has been proven that noni juice exhibits many pharmacological properties, including antioxidant, anti-inflammatory, and antitumor effects (16-19). Therefore, it is suggested that the antioxidant and anti-inflammatory properties of noni juice can provide a protective effect against oxidative stress-induced neurodegenerative diseases.

†These authors contributed equally to this work. 
Although protective effects of noni juice against scopolamine, B-amyloid, and streptozotocin-induced memory impairment caused by focal ischemia and rotenone in animals have been reported (20-21), there is no data available on the neuromodulatory potential and molecular mechanism of noni juice or its extracts on neuronal cell damage. Thus, for the first time, we investigated the neuroprotection and potential mechanism of noni juice extracts against tert-Butyl hydroperoxide (TBHP)-induced neurotoxicity in SH-SY5Y cells.

\section{Materials and methods}

\section{Preparation of noni juice extracts}

Noni juice (10 liters) was purchased from Noni Biological Engineering Development (Hainan, China). Noni juice was partitioned successively with chloroform, ethyl acetate, and n-butanol. Each fraction was evaporated in a vacuum to obtain a chloroform fraction $(\mathrm{CF}, 3.3 \mathrm{~g})$, an ethyl acetate fraction (EF, 5.3g), an nbutanol fraction $(\mathrm{BF}, 60.7 \mathrm{~g})$, and an aqueous fraction (AF, 64.8g).

\section{Chemicals and reagents}

TBHP and Rhodamine 123 were purchased from Sigma-Aldrich (St. Louis, MO, USA). An annexin V/ propidium iodide (PI) double staining kit was purchased from Nanjing KeyGen Biotech Co., Ltd. (Nanjing, China). Catalase (CAT), superoxide dismutase-1 (SOD-1), glutathione peroxidase (GPx), and glutathione reductase (GR) kits were obtained from Nanjing Jiancheng Bioengineering Institute (Nanjing, China). A Cell Counting Kit-8 was purchased from Biotool (Shanghai, China). 5-(and-6)-carboxy-2',7'-difluorodihydrofluorescein diacetate (H2DFFDA) was obtained from Invitrogen (Carlsbad, CA, USA).

\section{Animals}

Specific pathogen-free Sprague-Dawley rats were used for the acute oral toxicity tests. Male and female rats (3-weekold) were provided by the Institute of Experimental Animals, Chinese Academy of Medical Sciences (Beijing, China). Animals were housed in the animal house with a controlled temperature of $24 \pm 1^{\circ} \mathrm{C}$, relative humidity of $60 \pm 5 \%$, and a 12-hr light-dark cycle.

\section{Cell culture}

The SH-SY5Y human neuroblastoma cell line was purchased from the American Type Culture Collection (Rockville, MD, USA). The cells were cultured in Dulbecco's Modified Eagle Medium/Ham's F-12 (DMEM/ F12) supplemented with $10 \%$ fetal bovine serum (Gibco, Australia) and maintained at $37^{\circ} \mathrm{C}$ in a humidified atmosphere with $5 \% \mathrm{CO}_{2}$.

\section{Acute oral toxicity}

Ten liters of noni juice was freeze-dried to obtain $69.4 \mathrm{~g}$ of powder. The noni juice powder was dissolved in distilled water at $375 \mathrm{mg} / \mathrm{mL}$. Toxicity of the noni juice was assessed after a single oral administration in rats. The rats were randomly divided into two groups, each group with five males and five females. The rats were administered noni juice powder at $15,000 \mathrm{mg} / \mathrm{kg}$ body weight (BW) or the vehicle control (distilled water). Treatments $(20 \mathrm{~mL} / \mathrm{kg} \mathrm{BW})$ were administered a single dose by oral gavage. The single dose administration on the morning of Day 1 was followed by a 14-day observation period in which mortality or signs of morbidity were recorded for each animal. Animals were weighed immediately on Day 1 and again on Day 15 .

\section{Bacterial reverse mutation test}

Noni juice powder was assessed by two independent experiments for its potential to induce reverse mutation by the Ames test as described by Dillon GP (22). Genotoxicity was measured in Salmonella typhimurium strains TA 97, TA 98, TA 100, and TA 102. NJP was administered at $8,40,200,1,000$, and 5,000 $\mu \mathrm{g} /$ plate. All mutagenicity testing was performed in the presence or absence of the postmitochondrial fraction of liver homogenates (S9) from rats pretreated with Aroclor 1254.

\section{Determination of total phenolic, flavonoid, and polysaccharide contents}

The total phenolic (TPC) and flavonoid contents were determined according to the method of Wu CR et al. (23). The TPC contained in each sample was expressed as milligrams of gallic acid equivalents (GAE) and flavonoid amount was expressed as milligrams of rutin equivalents (RE). Polysaccharide content was determined by a spectrophotometric method at $485 \mathrm{~nm}$, modified from the method described by Li et al. (24). The amount of polysaccharide contained in each sample was expressed as milligrams of D-glucose equivalents (GE).

\section{Cytotoxicity of noni juice extracts and TBHP}

The Cell Counting Kit-8 assay was used to assess cell viability. SH-SY5Y cells were seeded into 96-well plates and allowed to adhere for $24 \mathrm{~h}$. To evaluate the cytotoxicity of TBHP, SH-SY5Y cells were treated by TBHP for $2 \mathrm{~h}$; then the drug was washed out and cells were incubated for $48 \mathrm{~h}$. After adhesion for $24 \mathrm{~h}, \mathrm{SH}-\mathrm{SY} 5 \mathrm{Y}$ cells were treated with noni juice extracts for $48 \mathrm{~h}$, and then the cytotoxicity of noni juice extracts was evaluated. The cell viability was determined using the Cell Counting Kit-8. In brief, $10 \mu \mathrm{L}$ CCK-8 solution was added to each well of the plate. Then, the plate was incubated at $37^{\circ} \mathrm{C}$ for an additional $3 \mathrm{~h}$. The absorbance of the WST- 8 formazan dye was measured at $450 \mathrm{~nm}$. The half maximal inhibitory concentration $\left(\mathrm{IC}_{50}\right)$ value was calculated from the nonlinear regression analysis. 
Effects of noni juice extracts on SH-SY5Y cells against TBHP-induced toxicity

To investigate the protective effect of noni juice extracts in TBHP-induced cell death, the cells were incubated with DMEM/F12 for $24 \mathrm{~h}$. After incubation with noni juice extracts for $4 \mathrm{~h}$, cells were treated with TBHP for $2 \mathrm{~h}$ and then exposed to noni juice extracts for $48 \mathrm{~h}$. Cell viability was measured by means of the CCK- 8 assay.

\section{Measurement of cellular antioxidant enzymes}

SH-SY5Y cells were seeded into $10-\mathrm{cm}$ culture dishes for $24 \mathrm{~h}$. After pretreatment of noni juice extracts for $4 \mathrm{~h}$, cells were incubated with TBHP for $2 \mathrm{~h}$ and then exposed to noni juice extracts for $48 \mathrm{~h}$. SH-SY5Y cells were collected from culture dishes and sonicated on ice. The solution was centrifuged for $15 \mathrm{~min}$ at $4{ }^{\circ} \mathrm{C}$ to eliminate cell debris, and the supernatant was used in enzyme activity assays. Antioxidant enzyme activities including CAT, GPx, GR, and SOD-1 were measured as described by Heng-Yin Ju et al. (25).

\section{Reactive oxygen species and mitochondrial membrane potential assays}

The method was performed according to the protocol previously published (26). To determine the effect of $\mathrm{CF}$ and AF on TBHP-induced reactive oxygen species (ROS) generation, SH-SY5Y cells were seeded into 6-well plates at a density of $3 \times 10^{5}$ cells/well and allowed to adhere for $24 \mathrm{~h}$. After incubation with $\mathrm{CF}$ or AF for $4 \mathrm{~h}$, cells were treated with TBHP for $2 \mathrm{~h}$ and then followed by the addition of various concentrations of $\mathrm{CF}$ or $\mathrm{AF}$ for $48 \mathrm{~h}$. Then the SH-SY5Y cells for the detection of ROS were incubated with $10 \mu \mathrm{mol} / \mathrm{L}$ 2',7'-dichlorodihydrofluorescein diacetate (H2DCFDA) at $37^{\circ} \mathrm{C}$ for $30 \mathrm{~min}$ in the dark. For the mitochondrial membrane potential assay, the SH-SY5Y cells were incubated with $0.5 \mathrm{mmol} / \mathrm{L}$ Rhodamine 123 at $37^{\circ} \mathrm{C}$ for $30 \mathrm{~min}$ in the dark. ROS generation was analyzed by a BD FACSCalibur cytometerwith the CELLQuest program.

\section{Reverse transcriptase-polymerase chain reaction}

The RNA (500 ng) was reverse-transcribed with the Moloney murine leukemia virus reverse transcriptase (Promega Corp., Madison, WI, USA) and oligo (dT)16 primer (Promega) in $20 \mu \mathrm{L}$ of reaction mixture. Each PCR primer used in this study was as follows (forward and reverse, respectively): heme oxygenase-1 (HO-1), 5'CTT GGC TGG CTT CCT TAC C-3' and 5'-CAT TGC CTG GAT GTG CTT T-3'; CAT, 5'-CCG ACG AGA TGG CAC ACT TTGACA-3' and 5'-CGC GAG CAC GGT AGG GAC AGT TC-3'; SOD-1, 5'-CCA TCA ATA TGG GGA CAA TACAC-3' and 5'-ACA CGA TCT TCA ATG GAC AC-3'; GAPDH, 5'-AGT GTA GCC CAG GAT GCC CTT-3' and 5'-GCC AAG GTC ATC CAT GAC AAC-3'.

\section{Western blot analysis}

The method was performed according to the protocol previously published (27). The level of $\beta$-actin was used as a loading control. The antibodies against superoxide dismutase 1 (SOD-1) (\#4266), Nrf2 (\#12721), cleaved/ total poly(ADP-ribose) polymerase-1 (PARP-1) (\#9532), and cleaved caspase-3 (\#9661) were obtained from Cell Signaling Technology, Inc. (Danvers, MA, USA). The antibody to $\beta$-actin (HC201) was obtained from TransGen Biotech (BeiJing, China).

\section{Detection of apoptotic cells by annexin}

$\mathrm{V}$-(fluorescein isothiocyanate, FITC)/PI

SH-SY5Y cells were seeded into six-well plates at a density of $3 \times 10^{5}$ cells/well and allowed to adhere for $24 \mathrm{~h}$. After incubation with noni juice extracts for 4 $\mathrm{h}$, cells were treated with TBHP for $2 \mathrm{~h}$, followed by the addition of various concentrations of CF for $48 \mathrm{~h}$. To quantify apoptosis, cells were stained with annexin $\mathrm{V}$ and PI using an annexin V-FITC/PI apoptosis kit (BD Biosciences, San Jose, CA, USA), following the protocol provided by the manufacturer. The fluorescence intensity was measured using a BD FACSCalibur flow cytometer according to the protocol previously published (28).

\section{Statistical analysis}

Results were expressed as the mean \pm SD from at least three independent experiments. One-way ANOVA was used to analyze the variance for the means of multiple groups. Student's $t$-test was applied for comparing the means of two groups. Statistical analysis was performed using SPSS 17.0 and significant differences were considered at values of $p<0.05$.

\section{Results}

\section{Acute oral toxicity}

During the 14-day single-dose acute toxicity study, no mortality or clinical signs of morbidity occurred in Sprague-Dawley rats with $15,000 \mathrm{mg} / \mathrm{kg} \mathrm{BW}$ of noni juice powder. Body weights of animals were unaffected by treatment (Table 1) and macroscopic examination of main organs showed no apparent abnormalities.

Table 1. Effect on body weight in rats acutely treated with noni juice

\begin{tabular}{lcccc}
\hline \multirow{2}{*}{$\begin{array}{l}\text { Noni juice } \\
\text { powder }(\mathrm{mg} / \mathrm{kg})\end{array}$} & Sex & $\begin{array}{c}\text { Number } \\
\text { dosed }\end{array}$ & & \multicolumn{2}{c}{ Body weight (mean \pm SD) } \\
\cline { 4 - 6 } & & & Day I & Day I5 \\
\hline 0 & M & 5 & $196.4 \pm 12.2$ & $274.9 \pm 11.4$ \\
0 & $\mathrm{~F}$ & 5 & $193.3 \pm 9.8$ & $230.4 \pm 10.3$ \\
15,000 & $\mathrm{M}$ & 5 & $198.5 \pm 13.3$ & $275.0 \pm 18.5$ \\
15,000 & $\mathrm{~F}$ & 5 & $192.0 \pm 11.8$ & $228.1 \pm 9.9$ \\
\hline
\end{tabular}




\section{Bacterial reverse mutation test (Ames test)}

The bacterial reverse mutation tests indicated that noni juice powder did not induce mutagenic activity toward any of the $S$. typhimurium strains with or without S9 activation at concentrations up to 5,000 $\mu \mathrm{g} /$ plate (Table 2).

\section{TPC, flavonoid, and polysaccharide contents}

TPC, flavonoid, and polysaccharide contents of noni juice extracts were measured systematically by spectrophotometric methods (Table 3). CF contained the highest TPC (284 mg of GAE/g CF) and a higher amount of flavonoids (156 mg of RE/g CF). Each gram of EF contained the highest amount of flavonoids (172 $\mathrm{mg}$ of RE) and higher amounts of TPC (255 mg of GAE). However, the amount of polysaccharide (584 mg of GE/g AF) contained in AF was more than other fractions.

Cytotoxic effects of noni juice extracts and TBHP on SH-SY5Y cells

To determine doses of noni juice extracts that could be used without adversely affecting cell viability, the latter was determined using the CCK-8 assay and plotted on the survival curves. The $\mathrm{IC}_{50}$ values of $\mathrm{CF}$ and $\mathrm{EF}$ for SH-SY5Y cells were 65.13 and $65.72 \mu \mathrm{g} / \mathrm{mL}$, respectively (Fig. 1a). No cytotoxicity or changes in cell morphology were observed with $10 \mu \mathrm{g} / \mathrm{mL} \mathrm{CF}$ or EF. The $\mathrm{IC}_{50}$ values for $\mathrm{BF}$ and $\mathrm{AF}$ were both greater than $0.5 \mathrm{mg} / \mathrm{mL}$. In order to evaluate the cytotoxicity of TBHP, SH-SY5Y cells were treated with different concentrations of TBHP $(5-500 \mu \mathrm{M})$ and a dose-dependent cell death was observed
(Fig. 1b). Concentrations of TBHP $\geq 50 \mu \mathrm{M}$ dramatically decreased cell viability and cell death reached $40 \%$ after $50 \mu \mathrm{M}$ TBHP treatment.

\section{CF and AF confer protection on SH-SY5Y cells against TBHP-induced toxicity}

In the present study, we evaluated the protective effect of noni juice extracts against TBHP challenge by CCK-8 assay. To determine the protective effects of noni juice extracts against TBHP-induced cytotoxicity, SH-SY5Y cells were preincubated with noni juice extracts for $4 \mathrm{~h}$, treated with TBHP for $2 \mathrm{~h}$, followed by treatment with noni juice extracts for $48 \mathrm{~h}$. With $50 \mu \mathrm{M}$ TBHP, only $60.6 \%$ of cells were viable as compared to the control group. However, as shown in Fig. 2, it was noteworthy that TBHP-induced cell death was significantly ameliorated by $\mathrm{CF}$ and AF treatments. Treatment with $10 \mu \mathrm{g} / \mathrm{mL}$ CF markedly improved

Table 3. TPC, flavonoid, and polysaccharide contents of noni juice extracts

\begin{tabular}{lccc}
\hline & $\begin{array}{c}\text { TPC } \\
(\mathrm{mg} \text { of GAE/g) }\end{array}$ & $\begin{array}{c}\text { Flavonoids } \\
(\mathrm{mg} \text { of RE/g) }\end{array}$ & $\begin{array}{c}\text { Polysaccharides } \\
(\mathrm{mg} \text { of GE/g) }\end{array}$ \\
\hline $\mathrm{CF}$ & $284.84 \pm 5.36$ & $156.32 \pm 10.11$ & nd \\
EF & $255.66 \pm 8.84$ & $172.07 \pm 6.89$ & nd \\
BF & $38.73 \pm 1.25$ & $14.0 \pm 0.23$ & $179.34 \pm 8.64$ \\
AF & $75.45 \pm 4.21$ & $8.64 \pm 0.18$ & $584.64 \pm 12.28$ \\
\hline
\end{tabular}

TPC, total phenolic content; GAE, gallic acid equivalents; $R E$, rutin equivalents; GE, D-glucose equivalents; $C F$, chloroform fraction; $E F$, ethyl acetate fraction; $\mathrm{BF}$, n-butanol fraction; $\mathrm{AF}$, aqueous fraction; nd, not detect.

Table 2. Salmonella typhimurium reverse mutation test for noni juice by the direct-plate incorporation method with and without S9 activation

\begin{tabular}{|c|c|c|c|c|c|c|c|c|}
\hline \multirow{3}{*}{$\begin{array}{l}\text { Noni juice } \\
\text { powder } \\
\text { (ug/plate) }\end{array}$} & \multicolumn{8}{|c|}{ Number of revertants/plate } \\
\hline & \multicolumn{2}{|c|}{ TA97 } & \multicolumn{2}{|c|}{ TA98 } & \multicolumn{2}{|c|}{ TAI00 } & \multicolumn{2}{|c|}{ TAI02 } \\
\hline & - & + & - & + & - & + & - & + \\
\hline \multicolumn{9}{|l|}{ Experiment I } \\
\hline 0 & $119.3 \pm 14.6$ & $116.0 \pm 12.5$ & $35.7 \pm 5.7$ & $40.0 \pm 3.0$ & $141.7 \pm 12.6$ & $144.3 \pm 13.1$ & $267.3 \pm 16$ & $261.3 \pm 8.1$ \\
\hline 8 & $122.3 \pm 17.5$ & $121.7 \pm 14.6$ & $36.0 \pm 3.6$ & $38.0 \pm 5.6$ & $147.0 \pm|7|$. & $145.0 \pm \mid 4.7$ & $266.7 \pm 15.5$ & $265.7 \pm 16.6$ \\
\hline 40 & $120.3 \pm 16.3$ & $125.7 \pm 10.6$ & $36.3 \pm 4.5$ & $39.0 \pm 4.6$ & $150.7 \pm 13.3$ & $144.3 \pm 18.5$ & $269.7 \pm 15.9$ & $266.0 \pm 13.1$ \\
\hline 200 & $120.0 \pm 10.0$ & $114.7 \pm 15.0$ & $39.3 \pm 3.1$ & $37.0 \pm 5.0$ & $150.3 \pm 20.6$ & $150.3 \pm 13.5$ & $267.7 \pm 18.0$ & $265.3 \pm 15.0$ \\
\hline 1,000 & $119.0 \pm 16.8$ & $123.0 \pm 12.2$ & $37.7 \pm 5.7$ & $39.7 \pm 5.0$ & $155.3 \pm 15.5$ & $154.3 \pm 15.0$ & $271.3 \pm 17.2$ & $267.7 \pm 12.3$ \\
\hline 5,000 & $120.3 \pm 10.0$ & $125.0 \pm 9.2$ & $37.7 \pm 3.1$ & $38.7 \pm 4.7$ & $156.7 \pm 13.3$ & $154.3 \pm 13.7$ & $269.7 \pm 13.3$ & $163.3 \pm 18.2$ \\
\hline Positive control & $1,270.0 \pm 81.9$ & $\mathrm{I}, 296.7 \pm 97 . \mathrm{I}$ & I,926.7 \pm 70.2 & I,826.7 \pm 94.5 & I,326.7 \pm 73.7 & $|, 336.7 \pm||| 2.4$ & $1,353.3 \pm 138.0$ & $920.0 \pm 60.0$ \\
\hline \multicolumn{9}{|l|}{ Experiment 2} \\
\hline 0 & $117.7 \pm 11.6$ & $120.0 \pm 14.0$ & $42.7 \pm 4.5$ & $41.7 \pm 4.2$ & $153.0 \pm 10.8$ & $146.3 \pm 12.7$ & $264.7 \pm 22.0$ & $267.7 \pm 11.6$ \\
\hline 8 & $123.3 \pm 10.4$ & $122.7 \pm 13.0$ & $39.0 \pm 4.6$ & $36.0 \pm 5.6$ & $158.3 \pm 14.7$ & $150.7 \pm 17.2$ & $270.0 \pm 11.4$ & $262.3 \pm 8.6$ \\
\hline 40 & $124.7 \pm 12.7$ & $|20.7 \pm 1| .0$ & $36.7 \pm 4.7$ & $37.7 \pm 5.5$ & $163.0 \pm 12.1$ & $152.3 \pm 17.8$ & $263.7 \pm 12.7$ & $270.7 \pm 13.7$ \\
\hline 200 & $120.3 \pm 15.6$ & $127.3 \pm 17.2$ & $39.0 \pm 2.6$ & $37.0 \pm 4.0$ & $155.0 \pm|6|$. & $143.3 \pm 12.3$ & $271.0 \pm 14.5$ & $265.7 \pm 13.9$ \\
\hline 1,000 & $124.7 \pm 9.1$ & $126.3 \pm 13.3$ & $39.7 \pm 5.5$ & $38.0 \pm 2.6$ & $160.3 \pm 16.0$ & $146.7 \pm 17.2$ & $271.7 \pm 18.5$ & $270.7 \pm 14.2$ \\
\hline 5,000 & $124.0 \pm 10.8$ & $119.3 \pm 17.8$ & $39.3 \pm 4.2$ & $40.7 \pm 4.7$ & $164.3 \pm \mid 2.1$ & $149.7 \pm 13.6$ & $264.3 \pm 18.9$ & $270.7 \pm 19.0$ \\
\hline Positive control & 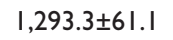 & $1,3|6.7 \pm 96|$. & 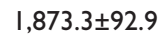 & $1,880.0 \pm 124.9$ & $1,270.0 \pm 117.9$ & $1,313.3 \pm 101.2$ & $1,436.7 \pm 106.0$ & $890.0 \pm 70.0$ \\
\hline
\end{tabular}


(a)

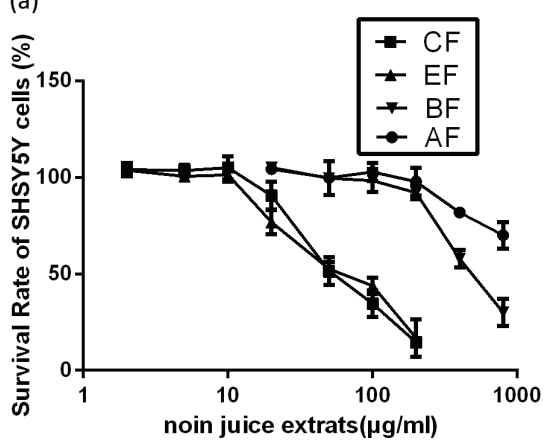

(b)

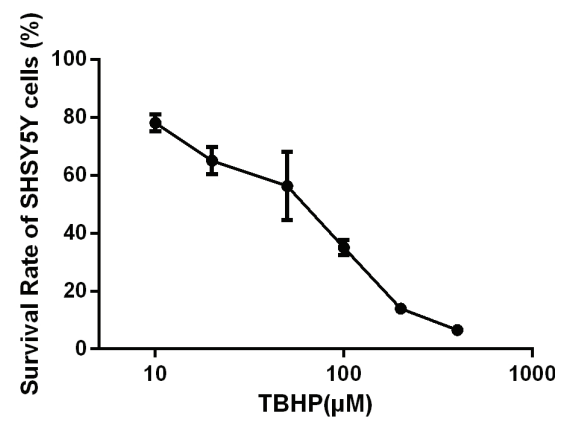

Fig. 1. Survival of SH-SY5Y cells treated with noni juice extracts and TBHP. (a) Survival of SH-SY5Y cells that were treated with noni juice extracts for $48 \mathrm{~h}$. (b) Survival of SH-SY5Y cells that were treated with TBHP for $2 \mathrm{~h}$. Data represent the mean \pm SD of three independent experiments. TBHP, tert-Butyl hydroperoxide.

(a)

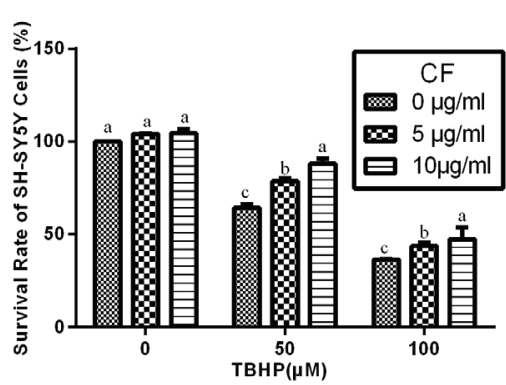

(c)

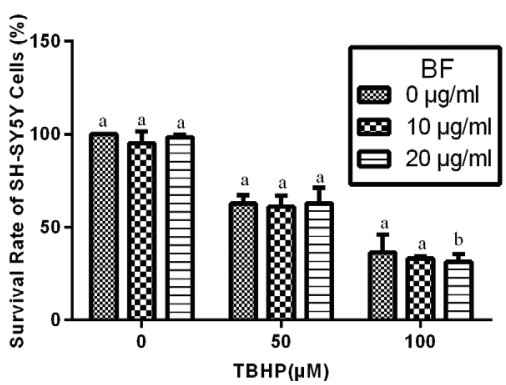

(b)

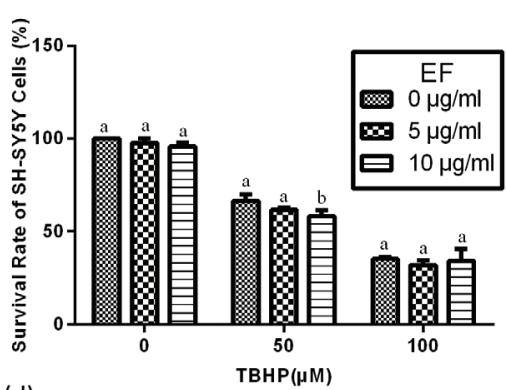

(d)

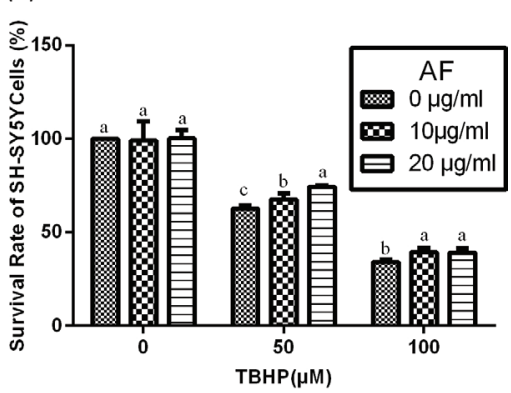

Fig. 2. Effects of noni juice extracts on TBHP-treated SH-SY5Y cells. After incubation with noni juice extracts for 4 h, SH-SY5Y cells were treated with TBHP for $2 \mathrm{~h}$ and then exposed to noni juice extracts for $48 \mathrm{~h}$. Data are expressed as mean \pm $\mathrm{SD}(n=3)$. ${ }^{\mathrm{a}-\mathrm{c}}$ The bars with different letters represent significant difference $(p<0.05)$, compared with each control group.

cell survival up to $87.8 \%$, and $20 \mu \mathrm{g} / \mathrm{mL}$ AF reestablished cell viability to $76.4 \%$. However, neither EF nor BF had any significant effect on cell viability.

\section{Effects of noni juice extracts on antioxidant enzymes activity in TBHP-treated SH-SY5Y cells}

In order to investigate whether antioxidant enzymes are involved in the removal of free radicals by noni extracts, SOD-1, CAT, GPx, and GR activities in SH-SY5Y cells were measured by the spectrophotometric degradation method. As shown in Table 4, oxidative damage induced by TBHP remarkably reduced the activity of antioxidant enzymes, while noni juice extracts pretreatment restored their activities almost similar to the control group, indicating that active ingredients in noni juice extracts have antioxidant defense ability (Table 4). Moreover, greater restoring capacity for antioxidant enzymes was observed in $\mathrm{CF}$ and AF groups, which was consistent with the result that $\mathrm{CF}$ and $\mathrm{AF}$ treatment conferred protection on $\mathrm{SH}$ SY5Y cells against TBHP-induced toxicity. CF exhibited the best restoring capacity for antioxidant enzymes. It is speculated that higher activity of antioxidant enzymes could attenuate ROS-induced cell damage more efficiently.

\section{CF and AF inhibits TBHP-induced ROS generation}

Further, the effects of CF and AF on TBHP-induced ROS generation were investigated. As shown in Fig. 3, compared with the control group, TBHP treatment markedly 
Table 4. Effects of noni juice extracts on SOD-1, CAT, GPx, and GR activity in SH-SY5Y cells exposed to $50 \mu \mathrm{M}$ TBHP

\begin{tabular}{lcccc}
\hline Samples & SOD-I $(\mathrm{U} / \mathrm{mg})$ & Catalase $(\mathrm{U} / \mathrm{mg})$ & $\mathrm{GPx}(\mathrm{mU} / \mathrm{mg})$ & $\mathrm{GR}(\mathrm{mU} / \mathrm{mg})$ \\
\hline Control & $43.2 \pm 2.93^{* *}$ & $1.84 \pm 0.16^{*}$ & $37.3 \pm 2.58^{* *}$ & $8.89 \pm 0.68^{* *}$ \\
$50 \mu \mathrm{MTBHP}$ & $18.7 \pm 3.79$ & $1.01 \pm 0.08$ & $23.0 \pm 2.08$ & $3.45 \pm 0.58$ \\
$5 \mu \mathrm{g} / \mathrm{mL} \mathrm{CF}+$ TBHP & $45.5 \pm 2.99 * *$ & $2.16 \pm 0.17^{* *}$ & $40.8 \pm 1.82^{* *}$ & $9.94 \pm 0.67 * *$ \\
$5 \mu \mathrm{g} / \mathrm{mL} \mathrm{EF+} \mathrm{TBHP}$ & $34.1 \pm 2.00^{* *}$ & $1.61 \pm 0.10^{*}$ & $30.2 \pm 2.42^{*}$ & $8.9 \pm 0.91 * *$ \\
$10 \mu \mathrm{g} / \mathrm{mL} \mathrm{BF+} \mathrm{TBHP}$ & $37.2 \pm 2.38^{* *}$ & $2.26 \pm 0.05^{* *}$ & $36.2 \pm 3.48^{* *}$ & $4.97 \pm 0.89 *$ \\
$10 \mu \mathrm{g} / \mathrm{mL} \mathrm{AF+} \mathrm{TBHP}$ & $43.0 \pm 3.79 * *$ & $2.07 \pm 0.06 * *$ & $40.1 \pm 1.75^{* *}$ & $9.7 \pm 1.31 * *$ \\
\hline
\end{tabular}

After incubation with noni juice extracts for $4 \mathrm{~h}, \mathrm{SH}-\mathrm{SY} 5 \mathrm{Y}$ cells were treated with TBHP for $2 \mathrm{~h}$ and then exposed to noni juice extracts for $48 \mathrm{~h}$. Data are expressed as mean \pm SD $(n=3)$. * $p<0.05$ and $* * p<0.01$ as compared to TBHP-treated cells.
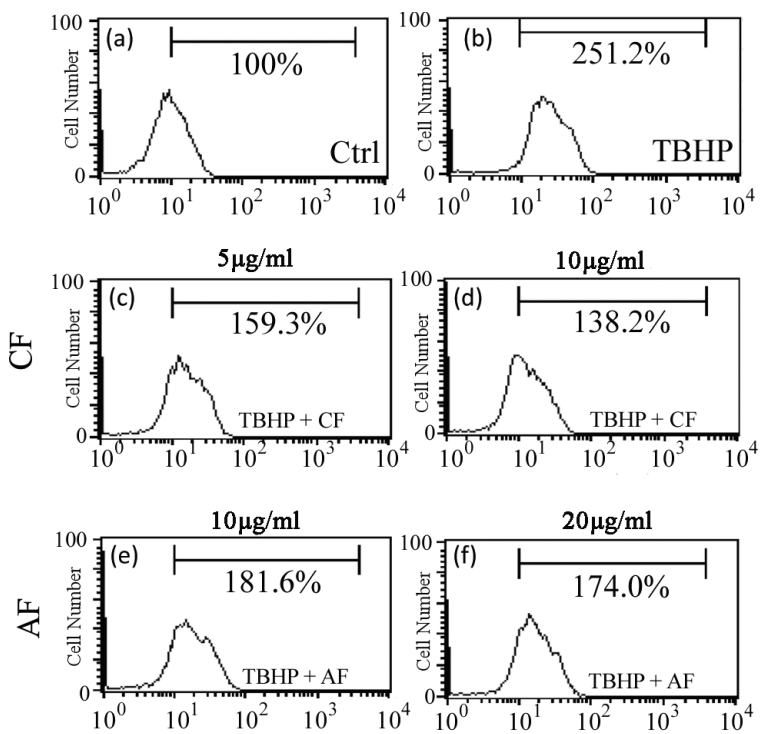

Fluorescence Intensity of CM- $\mathrm{H}_{2}$ DCFDA

Fig. 3. Effect of $\mathrm{CF}$ and $\mathrm{AF}$ on TBHP-induced ROS generation. SH-SY5Y cells were treated with (a) 0 , (b) $50 \mu \mathrm{M}$ TBHP, (c) $5 \mu \mathrm{g} / \mathrm{mL} \mathrm{CF}+50 \mu \mathrm{M}$ TBHP, (d) $10 \mu \mathrm{g} / \mathrm{mL} \mathrm{CF}+50 \mu \mathrm{M}$ TBHP, (e) $10 \mu \mathrm{g} / \mathrm{mL} \mathrm{AF}+50 \mu \mathrm{M}$ TBHP, (f) $20 \mu \mathrm{g} / \mathrm{mL}$ AF $+50 \mu \mathrm{M}$ TBHP. After treatment, the cells were stained with H2DCFDAfor 30 min and then analyzed by flow cytometry. $\mathrm{CF}$, chloroform fraction; $\mathrm{AF}$, aqueous fraction; ROS, reactive oxygen species.

increased the fluorescence intensity of SH-SY5Y cells to $251.2 \%$. However, $5 \mu \mathrm{g} / \mathrm{mL} \mathrm{CF}$ and $10 \mu \mathrm{g} / \mathrm{mL}$ AF significantly decreased the fluorescence intensity to 159.3 and $181.6 \%$, respectively. The results indicated that CF and AF could eliminate endogenous ROS in SH-SY5Y cells treated with TBHP efficiently.

\section{Inhibitory effects of CF and AF on TBHP-induced disruption of mitochondrial membrane potential (MMP)}

In order to examine whether the protection of $\mathrm{CF}$ and AF on SH-SY5Y cells against TBHP-induced toxicity involves the MMP pathway, measurement of MMP was carried out. Data showed that treatment with TBHP resulted in a marked decrease of MMP to $70.3 \%$, which demonstrated that TBHP induced the mitochondrial damage via depolarization of MMP. However, pretreatment with $5 \mu \mathrm{g} / \mathrm{mL} \mathrm{CF}$ and $10 \mu \mathrm{g} / \mathrm{mL}$ AF restored the MMP to 85.5 and $80.2 \%$, respectively. These results indicated that $\mathrm{CF}$ and AF potentially suppressed the depolarization of MMP and partially showed the protective effects against TBHP-induced toxicity (Fig. 4).

Effects of CF and AF on HO-I, CAT, and SOD-I gene expression To explore the molecular mechanism of $\mathrm{CF}$ and AF protection on SH-SY5Y cells, gene expression of antioxidants and Phase II detoxifying enzymes such as HO-1, CAT, and SOD-1 were analyzed by Reverse TranscriptionPolymerase Chain Reaction (RT-PCR). As shown in Fig. 5a, CF and AF treatment increased the expression of HO-1, CAT, and SOD-1 gene expression. Compared to the control group, treatment with $5 \mu \mathrm{g} / \mathrm{mL}$ CF upregulated HO-1, CAT, and SOD-1 gene expression 2.30-fold, 1.65fold, and 2.10-fold, respectively, while $10 \mu \mathrm{g} / \mathrm{mL}$ AF upregulated HO-1, CAT, and SOD-1 gene expression 1.28 times, 1.35 times, and 1.47 times, respectively (Fig. $5 \mathrm{~b}$ through d).

\section{Effect of CF and AF on Nrf2 nuclear translocation}

The activation of $\mathrm{Nrf} 2 /$ antioxidant response element (ARE) pathway is well known to confer resistance of cells to oxidative stress. In order to understand whether the upregulation of antioxidant enzymes and Phase II detoxification enzymes by $\mathrm{CF}$ and $\mathrm{AF}$ were related to activation of $\mathrm{Nrf2}$, the transactivation of Nrf2 in nuclear fractions was examined by Western blotting. As illustrated in Fig. 6a, CF and AF treatment obviously increased Nrf2 accumulation compared to the control group. A 3.16-fold increase in the nucleus Nrf2 was observed in the $10 \mu \mathrm{g} / \mathrm{mL} \mathrm{CF}$ treatment group by comparison with 2.35 -fold in the $10 \mu \mathrm{g} / \mathrm{mL} \mathrm{AF}$ group (Fig. 6b). It is likely that the Nrf2 signaling pathway is an important neuroprotective mechanism of $\mathrm{CF}$ and $\mathrm{AF}$ against TBHP-induced oxidative damage in SH-SY5Y cells.

\section{CF inhibited TBHP-induced apoptotic cell death}

To explore whether $\mathrm{CF}$ and $\mathrm{AF}$ conferring protection on SH-SY5Y cells against TBHP-induced toxicity was 
(a)

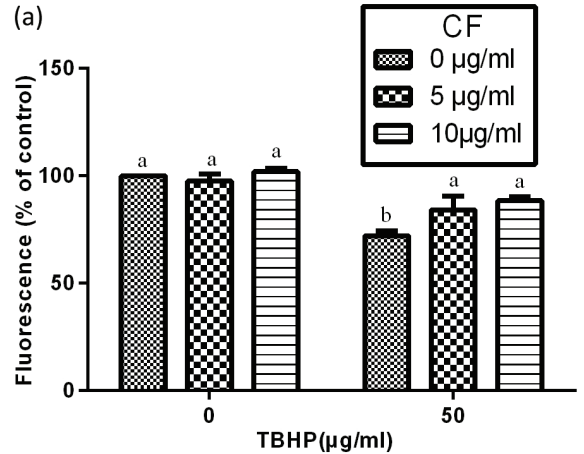

(b)

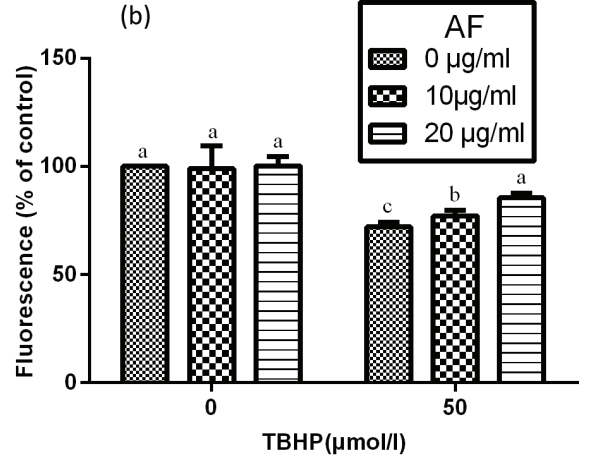

Fig. 4. Estimation of mitochondrial membrane potential in SHSY5Y cells. After incubation with CF or AF for 4 h, SH-SY5Y cells were treated with TBHP for $2 \mathrm{~h}$ and then exposed to CF or AF for $48 \mathrm{~h}$. After staining with Rhodamine 123 for 30 min, the cells were assayed with a FACSCalibur cytometer. Data are expressed as mean \pm SD $(n=3)$. ${ }^{\mathrm{a}-\mathrm{c}}$ The bars with different letters represent significant difference $(p<0.05)$, compared with each control group.

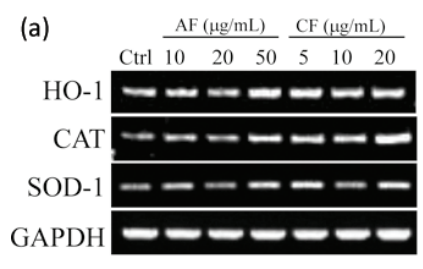

(c)





(d)

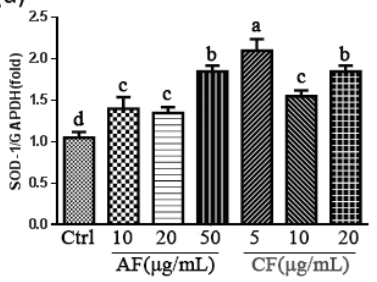

Fig. 5. Effects of $\mathrm{CF}$ and $\mathrm{AF}$ on HO-1, CAT, and SOD-1 gene expression. (a) SH-SY5Y cells were pretreated with AF and $\mathrm{CF}$ for $24 \mathrm{~h}$. Gene expression was analyzed by RT-PCR. (b) Quantification of HO-1 gene expression. (c) Quantification of CAT gene expression. (d) Quantification of SOD-1 gene expression. ${ }^{\mathrm{a}-\mathrm{f}}$ The bars with different letters represent significant difference $(p<0.05)$. HO-1, heme oxygenase-1; CAT, catalase; SOD-1, superoxide dismutase-1.

associated with apoptosis, the double-staining method using FITC-labeled annexin V and PI was performed. $\mathrm{CF}$ was chosen to investigate the mechanism of its protection on TBHP-induced cell apoptosis. As shown in Fig. 7a, the cell apoptosis rate of the control group was $1.41 \%$ and that of the $50 \mu \mathrm{M}$ and $100 \mu \mathrm{M}$ TBHP groups was obviously increased to 24.29 and $78.0 \%$. However, 10 $\mu \mathrm{g} / \mathrm{mL}$ CF treatment significantly reduced the TBHP-induced cell apoptosis rate of the $50 \mu \mathrm{M}$ and $100 \mu \mathrm{M}$ TBHP groups, respectively, to only 9.56 and $33.93 \%$. These results indicated that $\mathrm{CF}$ exhibited protective effects against oxidative stress-induced apoptosis.

In the present study, we examined whether THBP-induced cell death was mediated through native caspase- 3 cleavage and PARP-1 degradation and further explored the

(a)
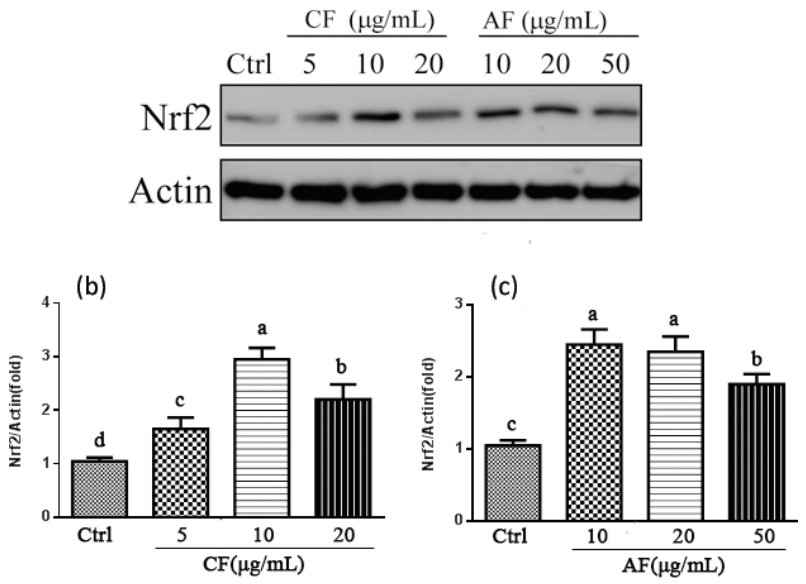

Fig. 6. Effect of $\mathrm{CF}$ and $\mathrm{AF}$ on the nuclear translocation of Nrf2. (a) SH-SY5Y cells were pretreated with $\mathrm{CF}$ and AF for $24 \mathrm{~h}$. Nuclear extracts were prepared and analyzed by Western blot. (b) Quantification of Nrf2 protein expression pretreated with $\mathrm{CF}$. (c) Quantification of Nrf2 protein expression pretreated with AF. ${ }^{\mathrm{a}-\mathrm{d}}$ The bars with different letters represent significant difference $(p<0.05)$.

molecular mechanisms of the neuroprotective effect of $\mathrm{CF}$ on THBP-induced apoptosis. As shown in Fig. 7b, cleaved caspase-3 protein and degradation of PARP-1 were undetected in the control group but appeared after exposure to TBHP. However, CF significantly prevented the activation of caspase- 3 and cleavage of PARP-1, indicating that CF could reverse the TBHP-induced apoptotic cell death efficiently. These results demonstrated that $\mathrm{CF}$ exhibited protective effects against TBHP-induced SH-SY5Y cells apoptosis through preventing activation of caspase-3.

\section{Discussion}

Although noni juice is well known as an antioxidant, the anti-oxidation effect and molecular mechanism of its extracts against oxidative damage in neurons are at present 
(a)
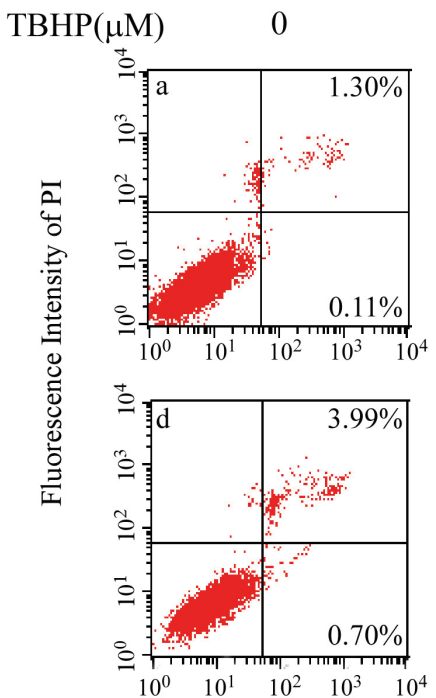
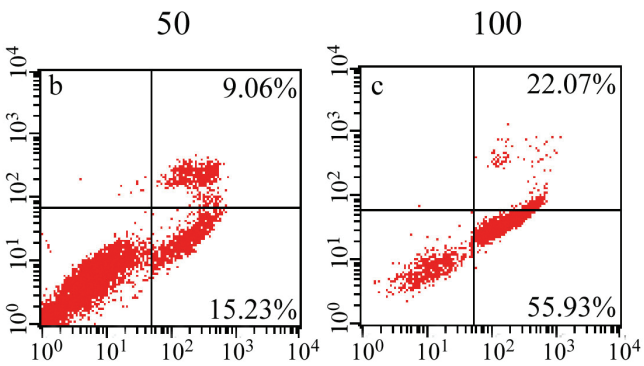

$\mathrm{CF}$

$(-)$
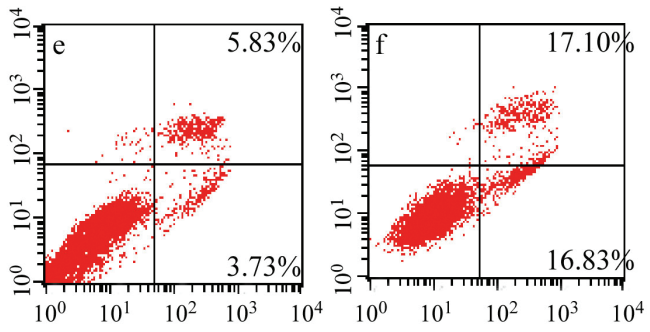

$(+)$

(b)

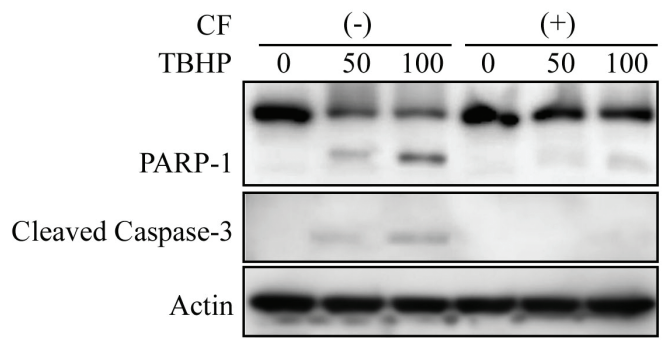

Fig. 7. Effect of CF on TBHP-induced apoptosis in SH-SY5Y cells. (a) Apoptotic cells were detected by annexin V and PI double staining and analyzed by flow cytometry. (b) Western blot analysis of the status of PARP-1 and cleaved caspase- 3 . $\beta$-actin was used as a loading control. A representative result of three independent experiments is shown. PARP-1, poly(ADP-ribose) polymerase-1; PI, propidium iodide.

unclear. In this study, SH-SY5Y cells with oxidative damage induced by TBHP were used as a model to explore the antioxidant and neuroprotective effects of noni juice extracts and reveal the underlying mechanism.

The acute oral toxicity and genotoxicity potential of noni juice were investigated. Noni juice did not induce mortality, clinical signs of morbidity, or physiologic abnormalities in Sprague-Dawley rats at a dose of 15,000 $\mathrm{mg} / \mathrm{kg} \mathrm{BW}$ and was also nongenotoxic at concentrations up to $5,000 \mu \mathrm{g} /$ plate. The results indicated that the maximum tolerated dose of noni juice was $>215.38 \mathrm{~mL} / \mathrm{kg}$ $\mathrm{BW}$ in rats. These results suggest low toxicity of noni juice in acute toxicity studies.

Phenolic compounds and Polysaccharides of valuable plants for health care and medicine have been proven to be the main classes of natural antioxidants and correlated with their antioxidant activities (29-32). Our present study showed that $\mathrm{CF}$ contained the highest amount of TPC, while AF had a higher content of polysaccharides than other fractions. Recent reports also indicate that TPC, flavonoids, and polysaccharides are the bioactive compounds present in noni juice, which are responsible for its antioxidant and other pharmacological properties (15-17).

Previous studies revealed that several herbal extracts could inhibit TBHP-induced cell loss efficiently $(33,34)$. In this study, pretreatment with $\mathrm{CF}$ and AF significantly prevented cell loss in a dose-dependent manner. However, $\mathrm{EF}$ and BF had no ability to improve cell viability. These results indicated that $\mathrm{CF}$ and $\mathrm{AF}$ protected $\mathrm{SH}-\mathrm{SY} 5 \mathrm{Y}$ cells in the presence of TBHP-induced oxidative stress. The high TPC and flavonoid content of CF may account for its antioxidant and neuroprotection potential, while AF may be rich in polysaccharides.

ROS is a major pathological factor that can lead to many serious diseases, including neurodegeneration and cardiovascular diseases. Intracellular ROS production disrupts redox balance or oxidative stress not only in relation to cell proliferation and signal transduction but also to inducing apoptosis $(35,36)$. Because ROS serves as an initiator of TBHP-induced toxicity, we measured intracellular ROS levels subsequently. Our results showed that CF 
and AF were able to inhibit TBHP-induced ROS generation, which indicated that the neuroprotective effects of $\mathrm{CF}$ and AF may be mediated by blocking ROS overproduction. CF reduced the apoptosis rate caused by TBHP, indicating that changes in ROS levels are essential for $\mathrm{CF}$ protection against TBHP-induced cell apoptosis. The results are similar to previous findings that demonstrate the ROS scavenging activity of Cyperus extract against $\mathrm{H}_{2} \mathrm{O}_{2}$-induced neuronal stress (37).

Antioxidant enzymes such as CAT, GPx, SOD-1, and GR play important roles in detoxifying ROS and maintaining redox status. Compelling evidence demonstrates that the activities of antioxidant enzymes decrease significantly in many neurodegenerative diseases (38). Perhaps the neuroprotective effects of noni juice extracts were related to antioxidant enzyme action. In order to further confirm the participation of antioxidant status, we examined their activities. $\mathrm{CF}$ and AF inhibited TBHP-induced reduction of SOD-1, CAT, GPx, and GR levels. The results demonstrated that the neuroprotective effects of CF and AF may partly be mediated through enhancing the antioxidant enzyme activity. Previous reports also showed that the neuroprotective effects of natural plants are associated with activation of antioxidant enzyme activity $(10,25)$.

$\mathrm{Nrf2}$ is a major regulator for ARE-driven antioxidant and Phase II detoxifying enzyme expressions, such as $\mathrm{NAD}(\mathrm{P}) \mathrm{H}$ quinone oxidoreductase 1 (NQO1), HO-1, CAT, and SOD-1. Increasing studies reveal that these antioxidant enzymes are regulated by activation of $\mathrm{Nrf} 2$ and play an important role in oxidative stress-induced neuronal injury (39-42). Our results showed that CF and AF treatment increased the nuclear translocation of Nrf2, which was also associated with elevated antioxidative enzyme expressions of HO-1, CAT, and SOD-1. In addition, induction of HO-1 expression was higher than that of SOD-1 and CAT, indicating that HO-1 may be a major factor exerting neuroprotective effects. It is hypothesized that promoting antioxidants and Phase II detoxifying enzymes via activating Nrf2 nuclear translocation might be responsible for CF and AF protecting SH-SY5Y cells from TBHP-induced oxidative damage.

A collapse of MMP is associated with several models of apoptosis and used to assess stress-induced apoptotic cell damage (43-45). Mitochondrial damage has been observed in Parkinson's disease by inhibition of Complex I activity, which results in mitochondrial impairment. Our results are in agreement with other reports that oxidative stress induced by TBHP impairs the mitochondrial membrane, resulting in the depolarization of MMP. CF and AF potentially restrained the depolarization of MMP induced by TBHP. In this study, we further explored the possible role of CF in TBHP-induced mitochondrial apoptosis.
TBHP-induced apoptosis mainly occurs via the apoptotic caspase pathway; apoptosis is induced by initiating mitochondrial dysfunction (46). Caspases are important mediators of cell death through the cleavage of many substrates. Caspase- 3 is an executioner for the death program in response to various stressors. Activated caspase- 3 catalyzes the degradation of PARP-1, which is an important ribozyme in DNA repair, cell proliferation, apoptosis, and transcription (47). The results in Fig. 7b show that CF protected TBHP-induced apoptosis via preventing caspase-3 activation.

In summary, this study demonstrated the antioxidant potential and molecular mechanisms involved in the neuroprotective effects of $\mathrm{CF}$ and AF. Our findings suggest that $\mathrm{CF}$ and AF can provide neuroprotection for SH-SY5Y cells against TBHP-induced oxidative damage and apoptosis through improving the antioxidant status, maintaining the mitochondrial membrane integrity, and regulating the apoptotic markers. Moreover, CF and AF could elevate antioxidant and Phase II detoxifying enzyme expression through activating the nuclear translocation of Nrf2, which may be the underlying molecular mechanism for protecting SH-SY5Y cells from TBHP-induced oxidative damage. It can be concluded that $\mathrm{CF}$ and $\mathrm{AF}$ are potential candidates for preventing neuronal-associated disorders mediated by oxidative stress. However, it is necessary to further explore the derivatized compounds in $\mathrm{CF}$ and $\mathrm{AF}$ with better neuroprotective activity, which should be investigated as a natural remedy for neurodegenerative disorders.

\section{Acknowledgments}

This work was supported by grants from the National Scientific Foundation of China (31471150) and Scientific and Technological Development Project of China, National Research Institute of Food and Fermentation Industries (No. KJ14-BS-02).

\section{Conflict of interest and funding}

The authors have not received any funding or benefits from industry or elsewhere to conduct this study.

\section{References}

1. Friedman J. Why is the nervous system vulnerable to oxidative stress? In: Gadoth N, Gobel HH, eds. Oxidative stress in applied basic research and clinical practice. The Humana Press, New York; 2011, pp. 19-27.

2. Bhat AH, Dar KB, Anees S, Zargar MA, Masood A, Sofi MA. Oxidative stress, mitochondrial dysfunction and neurodegenerative diseases; A mechanistic insight. Biomed Pharmacother. 2015; 74: 101-10.

3. Jiang T, Sun Q, Chen S. Oxidative stress: a major pathogenesis and potential therapeutic target of antioxidative agents in Parkinson's disease and Alzheimer's disease. Prog Neurobiol. 2016; 147: 1-19.

4. Chi-Rei W, Mei-Yueh H, Yung-Ta L, Heng-Yin J, Hui Ching. Oxidative stress and neurodegenerative disease. Neurosciences. 2014; 9(9): 19-23. 
5. Zawia NH, Lahiri DK, Cardozo-Pelaez F. Epigenetics, oxidative stress, and Alzheimer disease. Free Radical Biol Med.2009; 46(9): 1241-9.

6. Pringsheim T, Jette N, Frolkis A, Steeves TD. The prevalence of Parkinson's disease: a systematic review and meta-analysis. Mov Disord. 2014; 29(13): 1583-90.

7. Kalonia H, Kumar P, Kumar A. Attenuation of pro-inflammatory cytokines and apoptotic process by verapamil and diltiazem against quinolinic acid induced Huntington's like alteration in rats. Brain Res. 2011; 1372: 115-26.

8. Kalonia H, Kumar P, Kumar A. Licofelone attenuates quinolinic acid induced Huntington's like symptoms: possible behavioural, biochemical and cellular alterations. Prog Neuropsycho pharmacol Biol Psychiatry.2011; 35(2): 607-15.

9. Abushouk AI, Negida A, Ahmed H, Abdel-Daim MM. Neuroprotective mechanisms of plant extracts against MPTP induced neurotoxicity: future applications in Parkinson's disease. Biomed Pharmacother. 2017; 85: 635-45.

10. Peng S, Hou Y, Yao J, Fang J. Activation of Nrf2-driven antioxidant enzymes by cardamonin confers neuroprotection of PC12 cells against oxidative damage. Food Funct.2017; 8(3): 997-1007.

11. Je JY, Lee DB. Nelumbo nucifera leaves protect hydrogen peroxide-induced hepatic damage via antioxidant enzymes and HO-1/ Nrf2 activation. Food Funct. 2015; 6(6): 1911-18.

12. Zhang X, Wang L, Wang R, Luo X, Li Y, Chen Z. Protective effects of rice dreg protein hydrolysates against hydrogen peroxide-inducedoxidative stress in HepG-2 cells. Food Funct. 2016; 7(3): 1429-37.

13. Hu MX, Zhang HC, Wang Y, Liu SM, Liu L. Two new glycosides from the fruits of Morinda citrifolia. Molecules. 2012; 17(11): 12651-6.

14. Deng S, West BJ, Palu 'K, Jensen CJ. Determination and comparative analysis of major iridoids in different parts and cultivationsources of Morinda citrifolia. Phytochem Anal.2011; 22(1): 26-30.

15. Bittová $\mathrm{M}$, Hladůkova $\mathrm{D}$, Roblová $\mathrm{V}$, Krácmar $\mathrm{S}$, Kubán $\mathrm{P}$, Kubán V. Analysis of organic acids, deacetyl asperulosidic acid and polyphenolic compounds as a potential tool for characterization of noni (Morinda citrifolia) products. Nat Prod Commun. 2015; 10(11): 1817-20.

16. Z. Mohd Zin, A. Abdul Hamid, A. Osman, N. Saari \& A. Misran. Isolation and identification of anti oxidative compound from fruit of noni. Int J Food Properties. 2009; 10(2): 363-73.

17. Lin YL, Chou CH, Yang DJ, Chen JW, Tzang BS, Chen YC. Hypolipidemic and antioxidative effects of Noni (Morinda citrifolia L.) Juice on high-fat cholesterol-Dietary hamsters. Plant Foods Hum Nutr. 2012; 67(3): 294-302.

18. Basar S, Uhlenhut K, Högger P, Schöne F, Westendorf J. Analgesic and anti-inflammatory activity of Morinda citrifolia L. (Noni) fruit. Phytotherapy Res. 2010; 24(1): 38-42.

19. Nualsanit T, Rojanapanthu P, Gritsanapan W, Lee SH, Lawson D, Baek SJ. Damnacanthal, a noni component, exhibits antitumorigenic activity in human colorectal cancer cells. J Nutr Biochem. 2012; 23(8): 915-23.

20. Harada S, Hamabe W, Kamiya K, Satake T, Yamamoto J, Tokuyama S. Preventive effect of Morinda citrifolia fruit juice on neuronal damage induced by focal ischemia. Biol Pharm Bull. 2009; 32(3): 405-9.

21. Harada S, Fujita-Hamabe W, Kamiya K, Mizushina Y, Satake T, Tokuyama S. Morindacitrifolia fruit juice prevents ischemic neuronal damage through suppression of the development of post-ischemic glucose intolerance. J Nat Med. 2010; 64(4): $468-73$.
22. Dillon GP, Gaffney MA, Curran CM, Moran CA. Dietary safety of a dual-enzyme preparation for animal feed: acute and subchronic oral toxicity and genotoxicity studies. Regul Toxicol Pharmacol. 2017; 88: 106-17.

23. Chi-Rei W, Mei-Yueh H, Yung-Ta L, Heng-Yin J, Hui Ching. Antioxidant properties of Cortex Fraxini and its simple coumarins. Food Chem.2007; 104: 1464-71.

24. Li S, Shah NP. Characterization, antioxidative and bifidogenic effects of polysaccharides from Pleurotus eryngiiafter heat treatments. Food Chem. 2016; 197(Pt A): 240-9.

25. Ju HY, Chen SC, Wu KJ, Kuo HC, Hseu YC, Ching H, et al. Antioxidant phenolic profile from ethyl acetate fraction of Fructus Ligustri Lucidi with protection against hydrogen peroxide-induced oxidative damage in SH-SY5Y cells. Food Chem Toxicol. 2012; 50(3-4): 492-502.

26. Ou X, Chen Y, Cheng X, Zhang X, He Q. Potentiation of resveratrol-induced apoptosis by matrine in human hepatoma $\mathrm{HepG}_{2}$ cells. Oncol Rep. 2014; 32(6): 2803-9.

27. Chen J, Chen Y, He Q. Action of bleomycin is affected by bleomycin hydrolase but not by caveolin-1. Int J Oncol. 2012; 41(6): 2245-52.

28. Chen Y, Xu R, Chen J, Li X, He Q. Cleavage of bleomycin hydrolase by caspase-3 during apoptosis. Oncol Rep. 2013; 30(2): 939-44.

29. Wu CR, Lin WH, Hseu YC, Lien JC, Lin YT, Kuo TP, et al. Evaluation of the antioxidant activity of five endemic Ligustrum species leavesfrom Taiwan flora in vitro. Food Chem. 2011; 127: 564-71

30. Zhu F, Cai YZ, Sun M, Ke J, Lu D, Corke H. Comparison of major phenolic constituents and in vitro antioxidant activity of diverse Kudingcha genotypes from Ilex kudingcha, Ilex cornuta, and Ligustrum robustum. J Agric Food Chem. 2009; 57(14): 6082-9.

31. Hernández I, Alegre L, Van Breusegem F, Munné-Bosch S. How relevant are flavonoids as antioxidants in plants? Trends Plant Sci. 2009; 14(3): 125-32.

32. Wang J, Hu S, Nie S. Reviews on mechanisms of in vitro antioxidant activity of polysaccharides. Oxid Med Cell Longev. 2016; 13. doi: 10.1155 .

33. Choi BS, Sapkota K, Kim S, Lee HJ, Choi HS, Kim SJ. Antioxidant activity and protective effects of Tripterygium regelii extract on hydrogenperoxide-induced injury in human dopaminergic cells, SH-SY5Y. Neurochem Res. 2010; 35: 1269-80.

34. Lee DS, Keo S, Cheng SK, Oh H, Kim YC. Protective effects of Cambodian medicinal plants on tertbutyl hydroperoxideinduced hepatotoxicity via Nrf2mediated heme oxygenase1. Mol Med Rep. 2017; 15(1): 451-9.

35. Ramyaa P, Padma VV. Ochratoxin-induced toxicity, oxidative stress and apoptosis ameliorated by quercetin--modulation by Nrf2. Food Chem Toxicol. 2013; 62: 205-16.

36. Ramyaa P, Krishnaswamy R, Padma VV. Quercetin modulates OTA-induced oxidative stress and redox signalling in $\mathrm{HepG}_{2}$ cells-up regulation of $\mathrm{Nrf} 2$ expression and down regulation of NF-KB and COX-2. Biochim Biophys Acta. 2014; 1840(1): $681-92$.

37. Kumar KH, Khanum F. Hydroalcoholic extract of Cyperus rotundus Ameliorates H2O2-Induced Human Neuronal Cell Damage via its anti-oxidative and anti-apoptotic Machinery. Cell Mol Neurobiol. 2013; 33(1): 5-17.

38. Nikam S, Nikam P, Ahaley SK, Sontakke AV. Oxidative stress in parkinson's disease. Indian J Clin Biochem. 2009; 24: 98-101.

39. de Vries HE, Witte M, Hondius D, Rozemuller AJ, Drukarch B, Hoozemans J. Nrf2-induced antioxidant protection: a 
promising target to counteract ROS-mediated damage in neurodegenerative disease? Free Radic Biol Med. 2008; 45(10): 1375-83.

40. Chen PC, Vargas MR, Pani AK, Smeyne RJ, Johnson DA, Kan YW. Nrf2-mediated neuroprotection in the MPTP mouse model of Parkinson's disease: critical role for the astrocyte. Proc Natl Acad Sci USA. 2009; 106(8): 2933-8.

41. Rojo AI, Innamorato NG, Martín-Moreno AM, De Ceballos ML, Yamamoto M, Cuadrado A. Nrf2 regulates microglial dynamics and neuro inflammation in experimental Parkinson's disease. Glia. 2010; 58(5): 588-98.

42. Hara H, Ohta M, Adachi T. Apomorphine protects against 6-hydroxydopamine-induced neuronal cell death through activation of the Nrf2-ARE pathway. J Neurosci Res. 2006; 84(4): 860-6.

43. Lin YC, Huang YC, Chen SC, Liaw CC, Kuo SC, Huang LJ. Neuroprotective effects of ugonin $\mathrm{K}$ on hydrogen peroxideinduced cell death in human neuroblastoma SH-SY5Y cells. Neurochem Res. 2009; 34: 923-30.

44. Lee CH, Hwang DS, Kim HG, Oh H, Park H, Cho JH, et al. Protective effect of Cyperi rhizoma against 6-hydroxydopamine-inducedneuronal damage. J Med Food. 2010; 13: 564-71.
45. Doi K, Uetsuka K. Mechanisms of mycotoxin-induced neurotoxicity through oxidative stress-associated pathways. Int J Mol Sci. 2011; 12(8): 5213-37.

46. Cai L, Wang LF, Pan JP, et al. Neuroprotective effects of Methyl3,4-Dihydroxybenzoate against TBHP-Induced oxidative damage in SH-SY5Y Cells. Molecules. Molecules. 2016, 21(8):1-14.

47. Hassa, PO, Hottiger, MO. The diverse biological roles of mammalian PARPS, a small but powerful family of poly-ADP-ribose polymerases. Front Biosci. 2008; 13: 3046-82.

\section{*Chi Cheng}

cij123@126.com

China National Research Institute of Food and Fermentation Industries

\section{*Qiyang He}

qiyang_he@vip.163.com

Institute of biomedical technology

Chinese Academy of Medical Scieneces and Peking Union

Medical College 